Lautaro Ríos Álvarez*

Universidad de Valparaíso

Valparaíso, Chile

lautarorios@estudiorios.cl

\title{
El nuevo constitucionalismo latinoamericano**
}

The new Latin American constitutionalism

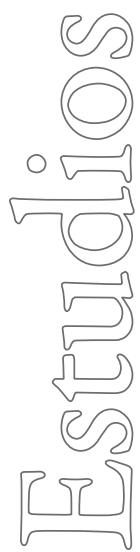

\section{Resumen}

${ }^{*}$ El autor fue Profesor de Teoría Politicay Derecho Constitucional de la Universidad de Valparaiso Chile y es Profesor Emérito de la misma, es Magister en Derecho Público por la Universidad de Chile, Doctor en Derecho por la Universidad Complutense de Madrid.
No existe constitucionalismo sin Constitución; ni existe Constitución sin un Estado en que ella tenga o vaya a tener aplicación. El Constitucionalismo Latinoamericano requiere, pues, de dos elementos esenciales: 1. La voluntad compartida por los países de Latinoamérica de "buscar la integración económica, politica, social y cultural de los pueblos de América Latina, con vistas a la formación de una comunidad latinoamericana de naciones" (Título I, parágrafo único, Constitución de Brasil); y 2. La elaboración de un proyecto de Carta Fundamental de la Unión de Estados Latinoamericanos que exprese esa voluntad, sus bases, sus fines y la manera de hacerla realidad. El logro del primero de estos elementos depende de la decisión del poder político del conjunto de los Estados de Latinoamérica. El segundo, en cambio, incumbe a los cultores del Derecho Constitucional de estos Estados, quienes somos los mejor capacitados y -por ende- los mayores responsables de llevar adelante esta tarea.

El primer paso en esta dirección debiera consistir en integrar a la reunión de las seis Asociaciones que nos convocan, al resto de las Asociaciones de Derecho Constitucional de Latinoamérica que hoy están ausentes de estas deliberaciones.

El segundo paso será establecer una Comisión permanente, integrada por constitucionalistas de todas o del mayor número de las naciones latinoamericanas, que estudie y proponga un programa de trabajo en que todos podamos formular proposiciones sobre la organización de dicha Comunidad Latinoamericana de Naciones, sobre las bases del o de los proyectos alternativos de la Constitución que regirá su destino. Este trabajo pretende bosquejar, a grandes rasgos, la tarea que nos espera si decidimos emprenderla.

** Artículo recibido el 30 de octubre de 2015 y aceptado para su publicación el 21 de noviembre de 2015". Ponencia presentada en las Jornadas de Asociaciones de Derecho Constitucional de América del Sur realizadas el 9 y 10 de abril de 2015 en Santa Cruz de la Sierra, Bolivia. 


\title{
Palabras claves
}

Constitucionalismos - Unión de Estados Latinoamericanos - Bases para una Constitución Latinoamericana.

\begin{abstract}
There is no constitutionalism without a Constitution; there is no Constitution without a State in which it has or will have application. The Latin American Constitutionalism thus requires two essential elements: 1. The shared desire by the countries of Latin America to "seek the economic, political, social and cultural development of the people of Latin America, with a view to the formation of a Latin American community of nations" (Title I, sole paragraph, Brazilian Constitution); and 2. The elaboration of a draft of the Constitution of the Union of Latin American States which express that will, their bases, their aims and how to achieve it. To achieve the first of these elements depends on the decision of the political power of all States in Latin America. The second, however, it is for the scholars of the Constitutional law of those States, who are the best trained and qualified - therefore the responsible for carrying out this task.

The first step in this direction should be to integrate the meeting of the six Associations that convene us, the rest of the Associations of Constitutional Law in Latin America that are now absent from these deliberations.

The second step will be to establish a Standing Committee, consisting of constitutionalists from all or from the majority of the Latin American nations, to study and propose a program of work that we can all make proposals on the organization of that Latin American Community of Nations and on the basis of the alternative draft or drafts of the Constitution that will govern its fate. This paper aims to outline broadly, the task that awaits us if we decide to undertake it.
\end{abstract}

\section{Key words}

Constitutionalisms - Union of Latin American States - Foundations of the Latin American Constitution 


\section{Introducción}

El constitucionalismo se puede concebir de dos maneras: como una construcción jurídica que busca poner límites a los poderes del Estado, sujetando su ejercicio a un código fundamental que cautela los derechos esenciales de las personas; o bien, como un movimiento político que procura controlar tales poderes mediante la puesta en práctica de ciertos principios comunes a los cultores de la democracia y del estado de derecho, tales como la separación de las funciones públicas en órganos distintos e independientes, la regulación estricta de sus competencias, la responsabilidad en el ejercicio del poder y el reconocimiento de los derechos fundamentales; todo ello bajo la sujeción de la actividad, tanto de los órganos estatales como de sus destinatarios, a las normas de supremo rango contenidas en la Constitución Política del Estado.

No existe un verdadero constitucionalismo sin una Constitución que le sirva de referente. $\mathrm{Ni}$ existe Constitución sin un Estado en que ella tenga o deba tener aplicación. De allí que, para nosotros, resulte sorprendente hablar de Constitucionalismo Latinoamericano en ausencia de una Carta -o al menos, de un Proyecto de Constitución de Latinoamérica- que refleje, a una vez, los valores, principios y normas a los que aspiramos que nos rijan y, principalmente, en ausencia de la convicción generalizada de pertenecer a una comunidad latinoamericana que se siente unida por vínculos solidarios, hermanada por lazos imperecederos y comprometida por el logro de un destino común.

Desde hace más de una década vengo abogando por la integración política latinoamericana ${ }^{1}$; y, en esta perspectiva, que es la única capaz de sacarnos del subdesarrollo y proyectarnos, unidos, como una de las grandes potencias que hoy gobiernan el mundo, el Constitucionalismo Latinoamericano debiera ser no solo el núcleo del esfuerzo intelectual que nos convoca cada cierto tiempo a intercambiar ideas sobre los problemas coyunturales que nos aquejan, sino también un cuerpo de proposiciones viables destinadas a contribuir a la estructura y contenido de un proyecto de Constitución para la Unión de Estados Latinoamericanos que, en algún momento, nos veremos en la necesidad imperiosa de construir.

Esta es mi manera de concebir el Constitucionalismo Latinoamericano.

\section{Actores aglutinantes de la unión Latinoamericana.}

A partir de 1969, año de nacimiento de la Comunidad Andina -y especialmente en las dos últimas décadas- se ha venido generando en Latinoamérica una cadena de acontecimientos de carácter político - como la Unión de Naciones Suramericanas (UNASUR), que integra a los doce países de esta región-; y de integración económica -como la Asociación Latinoamericana de Integración (ALADI) - que también reúne a doce Estados, con la mira de lograr un mercado común latinoamericano; pudiendo citarse, con el mismo

\footnotetext{
Ver nuestras ponencias: Ríos (2003); Ríos (2012).
} 
objetivo, el MERCOSUR, la COMUNIDAD ANDINA, la Alianza Bolivariana para los pueblos de América (ALBA), la Comunidad de Estados Latinoamericanos y Caribeños (CELAC) que reúnen a 33 Estados y la Alianza del Pacífico que ha obtenido resultados económicos espectaculares $\left({ }^{2}\right)$.

Otro importante factor integracionista digno de tomar en cuenta es la voluntad del constituyente de la inmensa mayoría de los Estados latinoamericanos de promover "la integración económica, política, social y cultural de los pueblos de América Latina, teniendo en vista la formación de una comunidad latinoamericana de naciones", como de una manera tan precisa como omnicomprensiva propugna la Constitución de Brasil ${ }^{3}$.

\section{Ventajas que implicaría la unión de los estados latinoamericanos.}

Estas ventajas admiten dos categorías: aquéllas que crean una nueva situación política de gravitación internacional; y aquéllas que disminuyen o ponen término a los obstáculos actualmente existentes para lograr esa Unión. Comenzaremos por las primeras.

3.1.La Unión de Estados Latinoamericanos sería el parto de un gigante político, económico y cultural con una población de alrededor de 606 millones de habitantes asentados sobre un territorio de 22.222.000 Kms. cuadrados ${ }^{4} y$ con un PIB calculado para el año 2014 en cerca de ocho billones de dólares (USD \$7.901.170.000.000)5.

Este territorio es rico en petróleo, carbón, cobre, hierro, estaño, oro, plata, litio, bórax, piedras preciosas y muchas otras substancias minerales. Posee abundantes bosques, producción agrícola, recursos hídricos ${ }^{6}$, pesquería, ganadería, potencial turístico y energía; posee, además, vastas extensiones inexploradas y es susceptible de un desarrollo sustentable 7

3.2. Sus habitantes están dotados de identidad de origen, de historia común, de religión predominante, de lenguaje similar, de tradiciones culturales, de intereses convergentes y de un destino común. Esta notable similitud constituye una evidente ventaja sobre los países de la Unión Europea los cuales -no obstante sus duros enfren-

\footnotetext{
Según el FMI las diez mayores economías son, en miles de millones de dólares: 1) EE.UU: 16.238.2) China: 13.623. 3) India: 5.032. 4) Japón: 4.779. 5) Alemania: 3.270. 6) Alianza del Pacífico: 3.075. 7) Rusia: 2.641. 8) Brasil: 2.467.9) Reino Unido: 2.391. 10) Francia: 2.290. "El Mercurio", Santiago de Chile, 13-VIII-2013, pg. B-6.

3 Ver las Constituciones de Argentina (Art. 75 No24), Bolivia (Art. 265-I), Brasil (parágrafo único del Título I), Colombia (Art. 9), Costa Rica (Art. 121 - 4), Ecuador (Art. 423: “Integración Latinoamericana”), Nicaragua (Art. 9), Paraguay (Art. 145), Perú (Art. 44), Uruguay (Art. 6º y Venezuela (Art. 153).

4 Solo las tierras cultivables de Latinoamérica se acercan al $13 \%$ de la superficie mundial; y las tierras de cultivo permanente alcanzan al $29 \%$ de la superficie mundial.

Ver Wikipedia: cálculo del PIB para los Países de Latinoamérica, año 2014.

6 Latinoamérica alberga cerca de un tercio de las aguas dulces del planeta, sin contar su dominio en el territorio antártico.

"En una gran economía interamericana, en marcha, en la que la riqueza de todos es una preocupación comín, poco importaría dónde son producidos el acero, los automóviles o los aviones, y dónde son cultivados el trigo o el maiz. Este es el caso actual, por ejemplo, en los ricos estados norteamericanos de Iowa y Kansas, que no tienen industrias de qué hablar y que son, dentro de la federación de los Estados Unidos, extraordinariamente prósperos". DÁvila (1956), p. 291.
} 
tamientos bélicos en el pasado, sus diferencias de origen, de religión, de lengua, de historias, de tradiciones y costumbres- lograron construir una plataforma de unidad.

3.3.La Unión de Estados Latinoamericanos nacería con un peso político del cual carecen absolutamente los estados llamados a constituirla. La Unión les permitiría tener una voz más potente en la ONU, asiento seguro en el Consejo de Seguridad y tratar en pie de igualdad con otras organizaciones multinacionales como la Unión Europea, la Unión Africana, la Asociación de Naciones del Sudeste Asiático, la Comunidad Económica y Monetaria de Africa Central, los miembros del Tratado de Libre Comercio de América del Norte, y con estados poderosos como EE.UU, China, la India o Japón.

3.4. La integración económica de los Estados Latinoamericanos le permitiría adquirir la tecnología necesaria para dar un salto cualitativo desde su actual economía basada principalmente en la exportación de materias primas hacia una economía industrial basada en la explotación de estas, en el comercio y exportación de productos elaborados y en la adopción y la creación de tecnologías propias.

Este progreso cualitativo elevaría considerablemente el valor del trabajo -que es uno de nuestros déficit endémicos- y mejoraría significativamente las expectativas y la calidad de vida de nuestros pueblos.

3.5.La Unión de las Naciones Latinoamericanas daría nacimiento a un gran Estado, dotado de un solo territorio común, sin fronteras divisorias, constituido por pueblos diversos pero hermanados en la vocación de construir la gran Patria Latinoamericana, que entierre para siempre las rencillas del pasado y donde imperen la unidad, la fraternidad y la solidaridad para afianzar nuestro destino común.

3.6. Entre las ventajas destinadas a terminar o a disminuir los obstáculos que nos separan, merece un lugar destacado el término de la absurda carrera armamentista entre nuestros países. La sola eliminación de los presupuestos de adquisición y mantenimiento de nuevas armas y del arsenal existente permitiría liberar ingentes recursos que la Unión podría destinar al desarrollo comunitario y a satisfacer necesidades de alto contenido social -como la educación, la salud y la vivienda - y que hoy por hoy se dilapidan en el mercado de las armas ${ }^{8}$.

3.7. Un gran Estado Latinoamericano sin fronteras internas -o solo las necesarias para efectos de policía- pondría término inmediato a las disputas fronterizas que hoy nos enfrentan y a veces enardecen y alteran la convivencia pacífica de nuestros pueblos.

Bolivia y Paraguay dispondrían de acceso a los océanos Pacífico y Atlántico y al mar Caribe, para dejar de ser países mediterráneos. Las aguas de la Cordillera de Los Andes, de

8 En su célebre intervención en la Cumbre de las Américas, Trinidad (18-IV-2009), el presidente de Costa Rica y ganador del Nobel, Oscar ARIAS, señaló -como causas de nuestro atraso- que en América Latina el promedio de escolaridad es de apenas 7 años pero, en cambio, gastamos la absurda cifra de $\mathbf{5 0 . 0 0 0}$ millones de dólares al año en armas y otros gastos militares. Citado por OppenheImer (2009), p. 231. 
los Campos de Hielo Sur y de los territorios antárticos de Chile y de Argentina estarían disponibles para la supervivencia y el desarrollo de todos nuestros pueblos.

En suma, nuestros países no tendrían que recurrir en el futuro a tribunales o árbitros internacionales para dirimir conflictos fronterizos ni para obtener accesos oceánicos, llegado el momento en que desaparecerían todas las fronteras que hoy nos dividen.

\section{Valores y principios compartidos por las naciones Latinoamericanas.}

Toda asociación política se organiza sobre la base de un conjunto armónico de valores y de principios jurídicos que conforman su identidad cultural, de un vínculo afectivo que une y motiva a sus miembros para permanecer unidos y de una finalidad que constituye el destino de la asociación.

El valor, en su significado filosófico, es la "cualidad queposeen algunas realidades, consideradas bienes, por lo cual son estimables. Los valores tienen polaridad en cuanto son positivos o negativos, y jerarquí en cuanto son superiores o inferiores"(Real Academia de la lengua).

Los principios jurídicos, en cambio, son los criterios directrices que orientan, de manera coherente, el contenido y la finalidad de las normas que regulan las relaciones humanas.

4.1. Valores compartidos por las naciones Latinoamericanas.

Las naciones de Latinoamérica iniciaron su vida independiente bajo el signo de la libertad.

A breve camino, en su historia de Estados soberanos, manifestaron su voluntad de vivir en un clima de igualdad y de justicia, aboliendo la esclavitud y los privilegios de casta y estableciendo tribunales independientes de la administración colonial, regidos por leyes autónomas.

El respeto a las diferencias religiosas, culturales, ideológicas y políticas que subsistirán entre los miembros de la Comunidad Latinoamericana, hace necesaria la vigencia del pluralismo en todo el ancho espectro de sus relaciones recíprocas.

Ha llegado el momento de abrir camino a la solidaridad, como valor indispensable para lograr la nivelación de nuestras asimetrías y el progreso equitativo de nuestros pueblos en su desarrollo futuro.

Todos estos valores deben estar presididos y orientados por el respeto a la dignidad de la persona humana que es la fuente, la medida y el objetivo final de los derechos fundamentales.

Es así que la Unión Latinoamérica de Naciones debe nacer y progresar bajo el imperio del respeto de la dignidad de la persona humana, de la libertad, la igualdad, la justicia, el pluralismo y la solidaridad, reconocidos como valores irrenunciables de su vida en comunidad, ya que ellos anidan en el espíritu de todos los pueblos de Latinoamérica. 
4.2.Principios internalizados en la conciencias jurídica de las naciones Latinoamericanas.

Revisando las Constituciones Políticas de los Estados Latinoamericanos se constata que son comunes a todos ellos los principios siguientes:

Como Estados de Derecho que son, rige en ellos el principio de legalidad o de juridicidad, aplicable por igual a las personas y a las autoridades públicas. Este principio conlleva el de responsabilidad, propio de todo Estado republicano. Y su aplicación supone el principio de publicidad de las normas, como requisito indispensable para que ellas sean vinculantes para todos.

Complementa la juricidad, que obliga por igual a gobernantes y gobernados, la interdicción de la arbitrariedad, es decir, la prohibición de que el capricho de las personas tenga primacía sobre el mandato de la ley que es la expresión de la voluntad popular.

Rige también, en todos nuestros países, el principio de supremacía de la Constitución sobre las leyes y sobre todas las normas que le están subordinadas. Este principio también se conoce bajo su fórmula más amplia de "jerarquía normativa”.

El principio de irretroactividad de las leyes sancionadoras en general y de las leyes penales, en particular, constituye una garantía generalizada de la seguridad jurídica que es la finalidad principal de todo ordenamiento normativo.

Las naciones Latinoamericanas se han constituido como repúblicas democráticas en que se respetan los derechos políticos de los ciudadanos, el principio de la división de los poderes entendida como la separación de las funciones del Estado en órganos independientes, sin perjuicio del control externo del ejercicio del poder. También se propugna en nuestras repúblicas el principio de participación de la ciudadanía en todas las esferas de la vida política y social.

También se ha ido abriendo camino en nuestras Cartas Políticas el principio del desarrollo sustentable, que implica la preservación del medio ambiente y de los recursos naturales como la forma racional de asegurar la salud y el bienestar de nuestros pueblos y de las generaciones futuras.

Así pues, son principios jurídico-políticos comunes a nuestras repúblicas -que debieran incorporarse a las Bases de la Constitución de la Unión de Estados de Latinoamérica- el de legalidad, el de publicidad, el de responsabilidad, la jerarquía normativa, la irretroactividad de toda clase de normas sancionadoras o punitivas, la seguridad jurídica, el principio de división de los poderes, el control externo de su ejercicio legítimo, la interdicción de la arbitrariedad, el principio de participación de la ciudadanía en la vida pública y el desarrollo sustentable?.

\footnotetext{
El Tratado Constitutivo de UNASUR (Brasilia, 23-V-2008) establece en su Preámbulo, como "principios rectores" de la Unión: "irrestricto respeto a la soberania, integridad e inviolabilidad territorial de los Estados; autodeterminación de los pueblos; solidaridad; cooperación; paz; democracia; participación ciudadana y pluralismo; derechos humanos universales, indivisibles e interdependientes; reducción de las asimetrias y armonía con la naturaleza para un desarrollo sostenible".
} 
4.3. Principios propios de la Unión de Estados Latinoamericanos.

A los principios internos propios de los actuales Estados latinoamericanos independientes, es preciso agregar aquellos principios que deben orientar la normativa de la Unión -que llamaremos provisoriamente federativa- de tales Estados.

Nos parece que, en lugar preferente, debe figurar el principio de la igualdad jurídica de los Estados miembros. No se trata de una igualdad matemática, pues resulta evidente la diversidad de todos ellos en cuanto a población, territorio, potencial económico y otros recursos. La igualdad consiste en el igual derecho de todos ellos a participar en el gobierno, en el órgano legislativo y en los demás órganos que requiera la Unión, así como en su generación; y también, en el igual derecho a participar en todos los beneficios que ésta sea capaz de producir.

Otro principio que debiera considerarse es el respeto a la autonomía interna de los Estados miembros en los asuntos que sean de su exclusiva competencia. La Unión supone-obviamente- el ejercicio de la soberanía externa de la Unión por parte del órgano encargado de representarla en sus relaciones con los demás Estados y con los organismos internacionales o supranacionales, sean de nivel mundial o regional, quedando vedado su ejercicio a los Estados miembros de ella.

Una tercera idea directa que consideramos esencial incorporar es la solidaridad -signo emblemático de la Unión de nuestras naciones- que implica la colaboración y la ayuda recíproca extensible a todas las manifestaciones de la vida: la salud, la educación, el trabajo, la reducción de las asimetrías de toda clase entre nuestros pueblos, la protección de la naturaleza, el desarrollo sustentable y la seguridad interior y exterior de la Unión.

\section{Proposiciones para la Constitución Política de la unión de Estados Latinoamericanos.}

\subsection{Ideas acerca de su contenido general.}

Hablamos de la Constitución Política, es decir de la Carta Fundamental que consagrará el nacimiento de una nueva entidad política, con personalidad jurídica de derecho público internacional, que regulará el estatuto igualitario de todos sus miembros y que integrará -con carácter federativo- a todos los Estados independientes que se hallan situados en el territorio de Latinoamérica. Esta Carta fundacional deberá, además, crear los órganos apropiados y suficientes para el funcionamiento expedito del nuevo Estado, establecer sus respectivas competencias y prever la solución de los conflictos que entre aquellos puedan suscitarse. Deberá fijar las atribuciones y las limitaciones del gobierno de la Unión en el campo de las relaciones internacionales. Deberá también cautelar el principio de su supremacía normativa tanto en el orden interno como en el internacional y -en fin- regular el procedimiento adecuado para su reforma. 
Como no se trata de la Constitución de un Estado originario sino de aquella que, sin eliminar la soberanía interna ni privar de todo efecto a las Constituciones Políticas de los Estados miembros, los agrupa en una federación u otra figura que se considere más adecuada, la Constitución de la Unión deberá armonizar su preeminencia o supremacía con la vigencia subordinada de las Cartas Fundamentales de los Estados miembros; de manera que -tal como ocurre en los Estados federales- exista una órbita de competencia entregada exclusivamente a la Constitución de la Unión y otra órbita, armónica con la anterior y vinculante al interior de cada Estado, reservada a la competencia de este; pero sin que puedan admitirse contradicciones entre las disposiciones de estas y las de aquella.

Y como esta Unión comprende no solo a Estados unitarios, sino también a Estados federales, habrá que tener especial cuidado en armonizar la vigencia de tres categorías de ordenamientos constitucionales: el de las provincias o Estados federados, el de los Estados federales y unitarios actualmente existentes y el de la Unión de Estados Latinoamericanos.

Otro aspecto importante a considerar es que la Constitución no puede ser materia de un tratado regido por las normas de la Convención de Viena sobre el Derecho de los Tratados de 23-V-1969; es decir, que admita el retiro o la denuncia del Tratado por alguno de los Estados miembros o que empiece a regir después de ratificado por una fracción de los Estados que lo suscribieron.

El imperio de la Constitución creadora de un nuevo Estado vincula para siempre a su población, a su territorio, a sus recursos y a su soberanía, ninguno de cuyos elementos puede sufrir desmedro por la sola voluntad de una de sus partes en perjuicio irreparable de la integridad y la sobrevivencia de la Unión; ni puede sufrir retardos en su entrada en vigencia por demoras en su ratificación.

La Constitución debe ser el resultado del acuerdo de una gran asamblea constituyente con participación de todos los Estados miembros, a través de delegados revestidos de plenos poderes para aprobarla, sin perjuicio de su eventual ratificación mediante referéndum.

Finalmente, el texto de la Constitución deber ser sencillo; es decir, sucinto en su desarrollo, de fácil lectura y comprensión, sin aspirar a ser perfecto pero sí, perfectible. No olvidemos que la Constitución de los Estados Unidos de Norteamérica - que lleva ya dos siglos y un cuarto de vigencia- contiene apenas siete artículos divididos en secciones y que son más numerosas sus enmiendas (XXVII) que su articulado ${ }^{10}$.

\subsection{Ideas para una posible estructura de la Constitución Latinoamericana.}

Yo invito a los constituyentes que crearán la nueva Constitución -y, especialmente, a mis hermanos constitucionalistas de toda América- a ser originales en la estructura y en el contenido de ella ${ }^{11}$.

10 No es el único caso de Constitución breve o sumaria de naciones multitudinarias. La de la República Popular China de 1978 -que regía a más de 1.000 millones de personas- tenía 60 artículos.

11 AlBeRDi (2002), p. 21, dijo: "La Constitución que no es original es mala, porque debiendo ser la expresión de una combinación especial de hechos, de hombres y de cosas, debe ofrecer esencialmente la originalidad que afecte esa combinación en el país que ha de constituirse". 
Les invito a no reproducir esquemas constitucionales del pasado, en que se repite el viejo esquema que comienza definiendo la forma del Estado, los límites de su territorio, la tipología de su gobierno y otros pormenores organizativos.

El principal signo del tiempo en que vivimos y que esperamos sea el centro de gravedad de la Unión de nuestros Estados es la dignidad de la persona humana, valor en sí mismo definitorio del ser humano; y, además, fuente primigenia y objetivo final de los derechos fundamentales que se le atribuyen por su causa.

El Estado ha sido hecho para servir al ser humano y no este para servir al Estado.

La persona humana y su dignidad, la familia y su dignificación, el bien común como finalidad de nuestra asociación política, la participación igualitaria de todos en la actividad pública, debieran presidir la Primera Parte de la Constitución. Seguidamente, podría incorporarse el estatuto constitucional de la nacionalidad y luego el de la ciudadanía Latinoamericana; los derechos y deberes de los titulares de ambas categorías, así como su forma de adquisición y las causales de su pérdida, suspensión y rehabilitación, en su caso. A continuación, debiera figurar el catálogo de los derechos y garantías que la Constitución reconoce y asegura, así como la enunciación de las acciones y recursos jurisdiccionales que contemple para protegerlos eficazmente.

En una Segunda Parte -sin perjuicio de que se adelante en el Preámbulo- cabría la definición jurídica de la Unión, sus objetivos, los valores que propugna y los principios que presidirán su desenvolvimiento -a los que nos referimos en el capítulo anterior-; su relación jerárquica y el reparto de competencias con los estados miembros, la naturaleza republicana y democrática de la Unión ${ }^{12}$, el asiento de su soberanía y las demás bases institucionales de la organización; la relación igualitaria entre los Estados miembros y la prohibición de estos de unirse o de establecer relaciones diplomáticas con otros Estados o de fraccionarse sin autorización expresa de la Unión.

En una Tercera Parte habría que referirse a los órganos de la Unión y -en capítulos separados- a la composición de cada uno de ellos, a la manera de generarlos y -especialmente- a la forma de elección de sus órganos gubernativo y legislativo ${ }^{13}$, la competencia de cada órgano, la eventual coexistencia de una especie de Corte Suprema Federal de la Unión con las Cortes Supremas de los estados miembros o bien la creación de una justicia federal paralela a la de los estados constitutivos; problema éste de delicada consideración por sus consecuencias orgánicas en el sistema judicial de Latinoamérica.

12 El Art. 1 de la Carta Democrática Interamericana (O.E.A. 11-XII-2001) dice: "La democracia es esencial para el desarrollo social, politico y económico de los pueblos de las Américas". Y el Art. 3 prescribe: "Son elementos esenciales de la democracia representativa, entre otros, el respeto a los derechos humanos y las libertades fundamentales; el acceso al poder y su ejercicio con sujeción al estado de derecho; la celebración de elecciones periódicas, libres, justas y basadas en el sufragio universal y secreto como expresión de la soberania del pueblo; el régimen plural de partidos y organizaciones politicas; y la separación e independencia de los poderes públicos".

13 El Art. 17 del Tratado Constitutivo de UNASUR dice: "La conformación de un Parlamento Suramericano con sede en la ciudad de Cochabamba, Bolivia, será materia de un Protocolo Adicional al presente Tratado”. 
En una Cuarta Parte cabría establecer la fórmula de financiamiento de la Unión, la formación de su presupuesto y las reglas de su administración, las sanciones a los estados miembros que retarden sus aportes y todo lo necesario para asegurar el gobierno efectivo y la administración eficaz de los recursos de la Unión, incluyendo la facultad de ésta para establecer y recaudar impuestos, contribuciones y tarifas, para contratar empréstitos, pagar sus deudas y proveer a la defensa, la seguridad y el bienestar general de los miembros de la Unión.

Una Quinta Parte podría destinarse a regular las relaciones internacionales de la Unión con otros Estados, asociaciones de Estados u organismos internacionales, tanto en lo político, cultural, económico, social, financiero y en cualquier otra área que sea de interés para la Unión; la potestad de integrarse con otras Uniones o federaciones de Estados, las condiciones y objetivos de tal integración, la de aceptar la incorporación a ella de otros estados así como las restricciones, limitaciones o precisiones que se estime conveniente establecer, como las que se refieran a la integridad de su soberanía, del territorio y a la defensa de sus recursos y de los derechos de sus habitantes.

Una Sexta Parte y final debiera destinarse a determinar las reglas de procedimiento de la reforma de la Constitución de la Unión., así como el plazo mínimo de vigencia de la Carta Constitutiva y de sus eventuales reformas, a fin de asegurar su estabilidad.

Las ideas generales que anteceden no tienen otra pretensión que la de demostrar que una Constitución Latinoamericana es perfectamente factible con tanta o con mejores razones que concurrieron a la Constitución de los Estados Unidos de Norteamérica en el siglo XVIII, o la Constitución de la República de Sudáfrica a fines del siglo XX.

La condición esencial para que nazca la Unión de los pueblos de Latinoamérica es que madure en todos ellos la convicción de su necesidad y de su conveniencia. A nosotros, cultores del Derecho Público, nos incumbe la tarea de demostrar que ella es jurídica y políticamente posible.

\section{Conclusión.}

Quien lea los capítulos que anteceden sin la fe ni la convicción de la necesidad de unir a nuestros Estados latinoamericanos dispersos, para potenciarlos en lo que merecen ser estando unidos, y sin la confianza en que es posible lograrlo, podrá pensar que todo lo dicho es el sueño de un iluso.

Nada sería más equivocado. Lo dicho es la expresión del más crudo realismo que puede resumirse así: Como Estados divididos no valemos ni pesamos en el mundo global. Solo unidos podremos lograr el desarrollo cultural y la calidad de vida que nuestros pueblos merecen. Solo unidos llegaremos a adquirir la gravitación internacional de la que carecemos separadamente. 
Pero mientras permanezcamos divididos, seguiremos siendo presa fácil de la explotación foránea de nuestras materias primas, víctimas ingenuas de la carrera armamentista, protagonistas de rencillas fronterizas insensatas y testigos impasibles e impotentes del atraso cultural y tecnológico, y del deficiente nivel de vida de nuestros pueblos. Si continuamos así, otra vez habremos desperdiciado la oportunidad de treparnos al carro de la historia.

Dijo Eduardo FREI MONTALVA, ex Presidente de Chile, que es necesario: "Saber que solitarios y aislados nuestros paises tienen un destino muy limitado, y que sólo una comunidad latinoamericana de naciones, verdaderamente integrada, será capaz de crear las condiciones humanas y económicas indispensables para constituir un mercado idóneo y amplio, sin lo cual en estos paises no habrá desarrollo, ni independencia real, ni defensa de sus legitimos intereses, ni posibilidad de ingresar en la aventura de la creación cientifica y de sus aplicaciones tecnológicas, para tener una voz en el ámbito de la comunidad mundial" 14 . Estas palabras, pronunciadas hace casi cuatro décadas, tienen hoy más vigencia que nunca.

También nuestra visión realista nos indica que el camino para alcanzar la unidad será áspero, largo y accidentado; pero es, precisamente por eso, que alguna vez tenemos que iniciar su recorrido.

Dijo José MARTÍ, en ocasión solemne: “... así está Bolívar en el cielo de América, vigilante y ceñudo, sentado aún en la roca de crear, con el Inca al lado y el haz de banderas a los pies; así está él, calzadas aún las botas de campaña, porque lo que él no dejó hecho, sin hacer está hasta hoy: porque Bolívar tiene que hacer en América todavía" ${ }^{15}$.

Nunca será tarde para realizar el sueño de Bolívar. Nunca será tarde para permitir que, por fin, el espíritu de Bolívar descanse en paz.

\section{Referencias Bibliográficas}

Alberdi, Juan Bautista (2002): "Bases y Puntos de Partida para la Organización Política de la República Argentina”, en: Acad. Nacional de Derecho y Ciencias Sociales de Córdoba, Argentina.

Bouzas, Roberto (2007): "Crisis y Perspectivas de la integración sudamericana”, en: Foreign Affairs, en español, octubre - diciembre.

Brewer-Carias, Alan (1968): Los Problemas Constitucionales de la Integración Económica Latinoamericana. Ed. Banco Central de Venezuela, Caracas.

Campos, Jorge (1984): Bolívar, Ed. Salvat, Barcelona.

Cardona, Diego (2005): “'Tiene futuro la Comunidad Sudamericana de Naciones?”, en: Foreign Affairs, en español, vol. 5, № 5 .

14 Frei Montalva (1977), p. 298.

15 José Martí “Simón Bolívar”, cit. por Campos (1984), p. 193. 
DÁvila, Carlos (1952): Nosotros los de Las Américas, Edit. del Pacífico, Stgo. de Chile, 2a. Ed.

Frei montalva, Eduardo (1977): América Latina: Opción y Esperanza, ed. Pomaire, Barcelona.

Nuñez Poblete, Manuel (1998): Integración y Constitución: Problemas para la Justicia Constitucional europea y sudamericana, II Universidad de Roma - Consiglio Nazionale delle Ricerche.

Oppenheimer, Andrés (2009): Los Estados Desunidos de Latinoamérica, Ed. Algaba, Madrid,.

Ríos ALVAREZ, Lautaro (2003): "Globalización, Integración y Derecho Constitucional”, en Estudios de Teoría del Estado y Derecho Constitucional en honor de Pablo Lucas Verdú, Servicio de Publicaciones. Facultad de Derecho, Universidad Complutense de Madrid, Tomo II, pg. 1.261 y sig.

Ríos alvarez, Lautaro (2012): "Bases Fundamentales para una Constitución Política de los Estados de América del Sur"-- Publicada en: Tomo I del Congreso Internacional de la Universidad de Valparaíso, Edeval, pg. 331.

\section{Información en la WEB:}

ALIANZA BOLIVARIANA PARA LOS PUEBLOS DE NUESTRA AMÉRICA (ALBA):

http://www.alianzabolivariana.org/modules.php?name=Content\&pa=show page\&pid $=2080$

\section{ALIANZA DEL PACÍFICO:}

http://es.wikipedia.org/wiki/Alianza_del_Pac\%C3\%ADfico

AREA DE LIBRE COMERCIO DE LAS AMÉRICAS (ALCA):

http://es.wikipedia.org/wiki/\%C3\%81rea_de_Libre_Comercio_de_las_ Am\%C3\%A9ricas

ASOCIACIÓN LATINOAMERICANA DE INTEGRACIÓN (ALADI):

http://www.aladi.org/nsfaladi/arquitec.nsf/VSITIOWEB/quienes_somos

CARTA DE LA ORGANIZACIÓN DE LOS ESTADOS AMERICANOS:

http://www.oas.org/dil/esp/tratados_A-41_Carta_de_la_Organizacion_de_los_Estados_Americanos.htm

CARTA DEMOCRÁTICA INTERAMERICANA: 
http://www.oas.org/charter/docs_es/resolucion1_es.htm

COMUNIDAD ANDINA:

http://www.comunidadandina.org/quienes.htm

COMUNIDAD DE ESTADOS LATINOAMERICANOS Y CARIBEÑOS (CELAC):

http://es.wikipedia.org/wiki/Comunidad_de_Estados_Latinoamericanos_y_ Caribe\%C3\%Blos

MERCOSUR:

http://www.mercosur.int/t_generic.jsp? contentid=655\&site $=1 \&$ channel=secretaria \&seccion $=2$

TRATADO CONSTITUTIVO DE LA UNIÓN DE NACIONES SURAMERICANAS:

http://www.comunidadandina.org/unasur/tratado_constitutivo.htm

UNIÓN DE NACIONES SURAMERICANAS:

http://es.wikipedia.org/wiki/Uni\%C3\%B3n_de_Naciones_Suramericanas

UNIÓN EUROPEA:

http://europa.eu/lisbon_treaty/glance/democracy/

ALMANAQUE MUNDIAL 2011, Ed. Televisa, México D.F., 2010.

ALMANAQUE MUNDIAL 2013, Ed. Televisa, México D.F., 2012.

ALMANAQUE MUNDIAL 2015, Ed. Televisa, México D.F., 2014.

DATOS ESTADÍSTICOS:

http://es.wikipedia.org/wiki/Am\%C3\%A9rica_Latina

http://es.wikipedia.org/wiki/Anexo:Pa\%C3\%ADses_de_Am\%C3\%A9rica_Latina_por_PIB_(PPA)_pasado_y_futuro 